\title{
EVALUATING THE POTENTIAL TRADE-OFF BETWEEN STUDENTS' SATISFACTION AND SCHOOL PERFORMANCE USING EVOLUTIONARY MULTIOBJECTIVE OPTIMIZATION
}

\author{
Oscar D. Marcenaro-Gutiérrez ${ }^{1}$, Sandra GonzÁlez-Gallardo ${ }^{2}$ And \\ MARIANO LUQUE ${ }^{3, *}$
}

\begin{abstract}
In this article, we carry out a combined econometric and multiobjective analysis using data from a representative sample of Andalusian schools. In particular, four econometric models are estimated in which the students' academic performance (scores in math and reading, and percentage of students reaching a certain threshold in both subjects, respectively) are regressed against the satisfaction of students with different aspects of the teaching-learning process. From these estimates, four objective functions are defined which have been simultaneously maximized, subject to a set of constraints obtained by analyzing dependencies between explanatory variables. This multiobjective programming model is intended to optimize the students' academic performance as a function of the students' satisfaction. To solve this problem we use a decomposition-based evolutionary multiobjective algorithm called Global WASF-GA with different scalarizing functions which allows generating an approximation of the Pareto optimal front. In general, the results show the importance of promoting respect and closer interaction between students and teachers, as a way to increase the average performance of the students and the proportion of high performance students.
\end{abstract}

Mathematics Subject Classification. 90C29, 90C11, 97D20, 62P20.

Received July 3, 2019. Accepted March 6, 2020.

\section{INTRODUCTION}

The relative low academic performance of secondary education students is a main concern for the educational authorities in Spain, as this country leads the ranking within the UE countries in terms of educational dropout rate and grade retention ${ }^{1}$. Specifically, Andalusia is among the Spanish regions that shows lower academic

Keywords. Evolutionary multiobjective optimization students' performance, students' satisfaction, achievement scalarizing function, econometric analysis.

1 Department of Applied Economics (Statistics and Econometrics), Universidad de Málaga, C/ Ejido, 6, 29071 Málaga, Spain.

2 Programa de Doctorado en Economía y Empresa de la Universidad de Málaga, C/ Ejido, 6, 29071 Málaga, Spain.

3 Department of Applied Economics (Mathematics) Universidad de Málaga, C/ Ejido, 6, 29071 Málaga, Spain.

* Corresponding author: mluque@uma.es

1 The percentage of students (aged between 6 and 16 years) who have repeated in Spain, at least once, is around $32 \%$. This figure is well above the actual average of OCDE, around $12 \%[18]$. 
performance in terms of standardized scores, like those provided by PISA ${ }^{2}$. Furthermore, this region - the most populated in Spain presents high dropout rates (around 31\% of boys and $24 \%$ of girls did not finish their studies, dropping out before finishing compulsory education in 2012; IECA, 2017 ${ }^{3}$ ). Additionally, since one of the key factors to explain economic growth is education [2], it is interesting to analyze any factor potentially contributing to improve the performance of the educational system. Regarding with this, one less explored factor is the satisfaction of students with different aspects of the teaching-learning process. This is precisely our main contribution, to the extent that we intend to explore how these qualitative aspects may contribute to achieve optimal combinations of different objective measures of educational performance. In this way we try to shed light to help policy makers to design optimal educational policies.

An increasing bulk of research is concerned with how academic performance can be measured, since the output of the teaching-learning process is multidimensional. In this sense, as a second contribution, this paper also provides evidence to the literature to date by considering several outputs simultaneously: the mean scores - at the school level - in reading and math, in addition to the percentage of students who exceed level three in $\mathrm{PISA}^{4}$ scores for these subjects, as the latest is considered the lower bound of the scores distribution for the most successful students - following the international large scale assessments. In this way, we account not only for the mean performance but also for its dispersion, which is on the base of the complex debate between efficiency and equity of any social policy.

The third contribution of the paper relies on the implementation of a combined econometric-multiobjective methodological approach, which allows to determine - in a more realistic way - to what extent the satisfaction of students should be considered a useful instrument to attain optimal-balanced improvements of the educational system performance. To achieve this, we have built a multiobjective programming model through an econometric analysis and solved our multiobjective problem using an evolutionary multiobjective algorithm called Global WASF-GA [21] with different scalarizing functions, which allows generating an approximation of the Pareto optimal front.

The rest of this paper is organized as follows. In Section 2, we present a review of the literature. The description of the data is found in Section 3, before presenting the first step of our methodological approach and the results of this econometric analysis, in Section 4. The concepts, mathematical notation and results of the multiobjective problem are reported in Section 5. Finally, the conclusions and policy implications of our results are drawn in Section 6.

\section{Literature REVIEW}

Traditionally the academic performance has been measured with the scores obtained by students in the main subjects [11]. However, to the extent that academic performance is a multidimensional output [4], using only the scores may be too simplistic. In general, the academic performance is the level of knowledge demonstrated in an area or subject taking into account the age and academic level. Additionally, Calero and Escardíbul [3] assert that the simple evaluation of knowledge does not include the total concept of academic achievement; they indicate that the academic performance can be measured, e.g. with the rate of grade retention and this depends to a large extent on social characteristics.

Broadly speaking, two theoretical approaches may be distinguished with regard to the outputs of the education production function. On the one hand, the more conservative perspective, which supports that the output of

\footnotetext{
2 According to PISA, this region is below the average for Spain and OCDE; Andalusia reaches 479 points in reading (the average for Spain and OCDE is 493), 473 in sciences (mean of Spain and OCDE, 496 and 493, respectively) and 466 in mathematics (mean of Spain and OCDE, 486 and 490, respectively).

${ }^{3}$ Institute of Statistics and Cartography of Andalusia. Instituto de Estadística y Cartografía de Andalucía.

${ }^{4}$ Following OECD [18], at level four students can use more complex or more abstract content knowledge, which is either provided or recalled, to construct explanations of more complex or less familiar events and processes. They can conduct experiments involving two or more independent variables in a constrained context. They are able to justify an experimental design, drawing on elements of procedural and epistemic knowledge. Level 4 students can interpret data drawn from a moderately complex data set or less familiar context, draw appropriate conclusions that go beyond the data and provide justifications for their choices.
} 
education depends only on academic factors. On the other hand, one that argues that social and family factors are also important for academic achievement, for example satisfaction with life and school center. Both perspectives can help to optimize academic performance [20].

In recent years, there is an increasing number of research works reporting a positive correlation between good results in education and life satisfaction of students [17,22]. Specifically, Suldo et al. [23] carried out a study in which they found significant correlation between students' satisfaction and the school climate. These authors consider six factors to encompass the concept of school environment: order and discipline, sharing of resources, parent involvement, peer relations, student-teacher relationship and fairness. Likewise, Uline and TschannenMoran [24] studied the relation between academic performance and school climate. This research work was conducted using USA data and analyzed the link between students' achievement in English and Mathematics and the quality of school facilities; they show a positive correlation between school environment and quality of facilities. With regard to satisfaction, Marcenaro et al. [15] provided a novel insight into the satisfaction of teachers as output of the educational production function, trying to find the level of inputs helping to achieve a balanced simultaneous solution to the problem of maximizing different outputs of the educational process. Similarly, Luque et al. [13] estimated simultaneously the performance in mathematics, English and Spanish literature as a function of sociodemographic characteristics of students and their parents. Additionally, there is evidence [10] that relates the degree of satisfaction of parents with the quality of the school and the scores that measure the progression of the students. These authors conclude that parents' satisfaction isstrongly related to scores and progression of children.

We depart from the previous literature to the extent that we are using a rich dataset focused on the satisfaction of students to evaluate how to achieve an optimal level of a multidimensional measure of academic performance, combining econometric estimates and multiobjective programming.

\section{DATA}

The empirical strategy in this paper is based on the data provided by the Agencia Andaluza de Evaluación Educativa (AGAEVE). In particular, this rich dataset provides information on the satisfaction of 8th grade students (aged 13-14 years) with 36 different aspects of the learning-teaching process: satisfaction with the image of the center, internal and external communications, involvement of education sectors and processes of the school. Nevertheless, we exclude from the analyses those satisfaction variables which had at least $5 \%$ of students with missing values, and those schools with a number of students - answering the satisfaction questions - below the $5 \%$ of the total sample of students. This means that we ended up with 20 satisfaction variables regarding the students enrolled in 162 secondary schools. With regard to the outputs of the education production function, the data provide the results from the diagnostic assessment test (DAT), which are the scores from a standardized test, similar to the one developed by PISA. The survey was answered by 7429 students, using a 0 to 10 scale.

Table A.1 shows the descriptive statistics of the variables under scrutiny. In this table, it can be observed that the average value of the satisfaction variables is around 6.8 points, with relatively low standard deviations. The maximum average value is reached by the variable "Knowledge of the rules of coexistence" with 7.62 points. This is followed by "Information received about the criteria established to obtain a title" and "Initial activities directed to the knowledge of the classmates as well as to the union of the group" with 7.36 points. The minimum value is reached by "Utility of the response given to the complaint or claim presented" with 5.72 points.

As the information on the satisfaction variables are reported grouped by schools, the rest of variables have been also grouped to this level. Specifically, the test scores used as output will be the average of the reading and mathematics scores, respectively, of all the students; same applies to the variables measuring the percentage of students that reached, at least, level four of academic achievement in math and reading, respectively. 


\section{ECONOMETRIC ANALYSIS}

In order to observe the correlation between student's satisfaction and the different measures of academic performance, we have estimated regression models - by ordinary least squares (OLS) - in which we consider four different dependent variables: mean scores in math, mean scores in reading and percentage of students (reaching level four or higher, i.e. achieving greater or equal to 559 points) in math and reading, respectively. The explanatory variables are those indicating the satisfaction of students with different aspects of the teaching-learning process, as above described. The dependent variables are standardized (mean of 0 and standard deviation of 1 ; using the mean and standard deviations for the whole sample of the corresponding variables.

The coefficients obtained from estimating the regression models are used to build the four objective functions that we wish to maximize simultaneously, thus having a multiobjective programming problem. The idea behind the OLS estimator is to minimize the squared sum term in order to get rid of the so-called statistical noise as much as possible. We are assuming that each of the four outputs is affected by random factors which are inherently unobservable and distributed normally.

If the order of the secondary education center is represented as " $i$ ", and the four outputs are indexed as " $j "$, this model can be represented by the following set of equations:

$$
\begin{aligned}
P_{j}(i) & =\widehat{\alpha}^{j}+\hat{\beta}_{1}^{j} x_{1}(i)+\hat{\beta}_{2}^{j} x_{2}(i)+\ldots+\hat{\beta}_{5}^{j} x_{5}(i)+\epsilon_{j}(i) \\
i=1, \ldots, n(n & =\text { number of observations, } 162 \text { education centers }) \\
j=1,2,3,4 & \begin{aligned}
1 & =\text { average maths scores; } 2 \text { = average reading scores; } 3 \\
& =\text { proportion of students above the level four in maths; } 4 \\
& =\text { proportion os students above the level four in reading) }
\end{aligned}
\end{aligned}
$$

where $P_{j}(i)$ is a measure of the output " $j$ " for the center " $i$ ", and $x_{1}(i), \ldots, x_{5}(i)$ a set of explanatory variables; $\epsilon_{j}(i)$ is a random disturbance; $\hat{\beta}^{j}=\left(\hat{\beta}_{1}^{j}, \ldots, \hat{\beta}_{5}^{j}\right)^{T}$ a vector of slope coefficients and $\widehat{\alpha}^{j}$ a fixed but unknown population intercept. From the estimation of the four regression models we obtain 5 significant regressors: respect and attention received by the teachers, satisfaction with the way teachers teach, information received on the personal and academic progression, assessment of the starting activities carried out at the beginning of the academic year and knowledge of the projects and educational activities of the center.

Table 1 shows the estimated coefficients of the group of significant variables for each of the four objective functions; it also reports the standard deviations and the significance levels for the estimated coefficients.

Regarding the results of the estimations, it can be seen that in all the estimations the variable respect received by the teaching staff is significant and with a positive coefficient, which means that it contributes to increase the academic achievement of students, both in terms of average scores and the percentage of students above level three in both subjects. The rest of the variables that are significant are not the same in the different estimations, which means that there is some degree of conflict when reaching the maximum of the objectives at the same time and, thus, it justifies the multiobjective approach implemented. A description of the variables under scrutiny is provided in Table A.2.

The rest of the explanatory variables that are significant have a negative coefficient, which means that an increase in these variables produces, on average, a decrease in the academic achievement. For example, focusing on the estimation whose dependent variable is scores in reading, the variables with significant coefficients are: initial activities and projects, which present negative coefficients. Therefore, if these variables increase by one (in a $0-10$ scale), the standard deviation of scores in reading will decrease by 0.345 and 0.236 , respectively; in other words, the dependent variable will decrease by $34.5 \%$ and $23.6 \%$ of a standard deviation, which is a quite substantial impact. For example, in the case of reading, this means between 10 and 15 points, which is equivalent to almost half academic year in terms of competences accumulation. 
TABLE 1. Estimates of the effect of students' satisfaction on students' academic outcomes (normalized).

\begin{tabular}{|c|c|c|c|c|}
\hline & $\begin{array}{l}\text { Normalized mean } \\
\text { scores in math }\end{array}$ & $\begin{array}{l}\text { Normalized mean } \\
\text { scores in reading }\end{array}$ & $\begin{array}{l}\text { Normalized } \% \\
\geq 559 \text { scores in } \\
\text { math }\end{array}$ & $\begin{array}{l}\text { Normalized } \% \\
\geq 559 \text { scores in } \\
\text { reading }\end{array}$ \\
\hline \multirow{2}{*}{$\begin{array}{l}\text { Respect and attention } \\
\text { received by the teachers }\end{array}$} & $0.696^{* * *}$ & $0.596^{* * *}$ & $0.515^{* * *}$ & $0.479^{* * *}$ \\
\hline & $(0.155)$ & $(0.136)$ & $(0.160)$ & $(0.141)$ \\
\hline \multirow{2}{*}{$\begin{array}{l}\text { Overall assessment of the } \\
\text { teacher's way of teaching }\end{array}$} & $-0.407^{* *}$ & & & \\
\hline & $(0.177)$ & & & \\
\hline \multirow{2}{*}{$\begin{array}{l}\text { Information received on the } \\
\text { personal and academic pro- } \\
\text { gression }\end{array}$} & $-0.277^{*}$ & & $-0.426^{* * *}$ & \\
\hline & $(0.152)$ & & $(0.134)$ & \\
\hline \multirow{2}{*}{$\begin{array}{l}\text { Initial activities directed to } \\
\text { the knowledge of the class- } \\
\text { mates and to the union of the } \\
\text { group }\end{array}$} & & $-0.345^{* * *}$ & & $-0.257^{* *}$ \\
\hline & & $(0.121)$ & & $(0.125)$ \\
\hline \multirow{2}{*}{$\begin{array}{l}\text { Knowledge of the projects and } \\
\text { educational activities of the } \\
\text { school }\end{array}$} & & $-0.236^{* * *}$ & & $-0.198^{* *}$ \\
\hline & & $(0.0901)$ & & $(0.0937)$ \\
\hline Constant & $\begin{array}{l}-0.0955 \\
(1.159)\end{array}$ & $\begin{array}{l}-0.251 \\
(1.038)\end{array}$ & $\begin{array}{l}-0.774 \\
(0.984)\end{array}$ & $\begin{array}{l}-0.291 \\
(1.080)\end{array}$ \\
\hline Observations & 162 & 162 & 162 & 162 \\
\hline$R$-squared & 0.138 & 0.181 & 0.076 & 0.114 \\
\hline
\end{tabular}

Notes. Standard errors in parentheses. Estimation method: OLS. Coefficient: ${ }^{* * *}$ significant at $1 \%,{ }^{* *}$ significant at $5 \%$, *significant at $10 \%$. Source: Authors' own calculations.

\section{SPECIFICATION AND RESOLUTION OF OUR MODEL}

\subsection{Concepts and notation in multiobjective programming}

In order to solve the multiobjective problem proposed in this study it is necessary to establish the basic definitions and notations about this topic. Let us consider the following general multiobjective problem:

$$
\begin{aligned}
& \max f(\boldsymbol{x})=\left(f_{1}(\boldsymbol{x}), \ldots, f_{k}(\boldsymbol{x})\right) \\
& \text { s.t.: } \quad \boldsymbol{x} \in X
\end{aligned}
$$

which involves $k(\geq 2)$ conflicting objective functions $f_{j}: \mathrm{X} \rightarrow \mathbb{R}$ that must be maximized simultaneously and where $\boldsymbol{x}=\left(x_{1}, \ldots, x_{m}\right)^{T}$ are the decision variables (if any function or functions must be minimized, the opposite function can be considered since that minimize a function is equivalent to maximize the opposite one). The decision vector $\boldsymbol{x}$ belongs to the called feasible region $X \subset \mathbb{R}^{\mathrm{n}}$, which we suppose that is a nonempty compact set. The image of any vector of decision $\boldsymbol{x} \in X, \boldsymbol{z}=f(\boldsymbol{x})$ is called objective vector and $Z=f(X)$ is called feasible objective region. In the majority of cases, it is impossible to find a feasible which simultaneously maximizes all objective functions due to the conflict degree among the objectives. Because of that, the efficiency concept of optimality appears where none of the components can be improved without deteriorating at least one of the others: a decision vector $\boldsymbol{x}^{\prime} \in X$ is defined as efficient or Pareto optimal solution of the problem (5.1) if there does not exist another $\boldsymbol{x} \in X$ such that $f_{j}\left(\boldsymbol{x}^{\prime}\right) \leq f_{j}(\boldsymbol{x})$ for all $j=1, \ldots, k$, with at least one 
strict inequality. When this happens, $\boldsymbol{z}^{\prime}=f\left(\boldsymbol{x}^{\prime}\right)$ is called nondominated objective vector or Pareto optimal objective vector. The efficient set is denoted by $E$ and $f(E)$ is the nondominated objective set or the Pareto optimal front. A decision vector $\boldsymbol{x}^{\prime} \in X$ is called weakly efficient or weakly Pareto optimal if there does not exist another $\boldsymbol{x} \in X$ such as $f_{j}\left(\boldsymbol{x}^{\prime}\right)<f_{j}(\boldsymbol{x})$ for all $j=1, \ldots, k$. The corresponding objective vector is called weakly nondominated objective vector. In addition, it is necessary to underline that the set of efficient solutions is a subset of the weakly efficient solutions.

Furthermore, since the set of nondominated objective vectors contains more than one vector - usually many solutions -, it is useful to know the ranges of the objective vectors in the nondominated objective set. On the one hand, lower bounds are set by the nadir vector $\boldsymbol{z}^{\text {nad }}=\left(z_{1}^{\text {nad }}, \ldots, z_{k}^{\text {nad }}\right)^{T}$, where $z_{j}^{\text {nad }}=\min _{\boldsymbol{x} \in E} f_{j}(\boldsymbol{x})$ for all $j=1, \ldots, k$, while upper bounds are given by the ideal values $\boldsymbol{z}^{*}=\left(z_{1}^{*}, \ldots, z_{k}^{*}\right)^{T}$, where $z_{j}^{*}=\max _{\boldsymbol{x} \in E} f_{j}(\boldsymbol{x})=$ $\max _{\boldsymbol{x} \in X} f_{j}(\boldsymbol{x})$ for all $j=1, \ldots, k$. The nadir vector is not easy to obtain and when estimated from the pay-off table the values achieved are not necessarily good approximations (for details, see e.g. [9]; or [16]). Deb et al. [7] and Deb and Miettinen [5] proposed more reliable approaches for its estimation. Both the ideal vector and the nadir vector are frequently used to normalize the objective functions since the range normalization is the most used one. In the case of this study, this normalization has been previously performed.

One of the most used techniques to generate Pareto optimal solutions in multiobjective programming is based on an achievement scalarizing function proposed by Wierzbicki [26]. Given some reference values $q_{1}, \ldots, q_{k}$ for the objective functions, which constitute the so-called reference point $\boldsymbol{q}=\left(q_{1}, \ldots, q_{k}\right)^{T}$ and, a vector of weights $\boldsymbol{\mu}=\left(\mu_{1}, \ldots, \mu_{k}\right)^{T}$ with $\mu_{j}>0$ for all $j=1, \ldots, k$ to reach these reference values, the achievement scalarizing function for problem (5.1) is given by the following expression:

$$
s(\boldsymbol{q}, f(\boldsymbol{x}), \boldsymbol{\mu})=\max _{j=1, \ldots, k}\left\{\mu_{j}\left(q_{j}-f_{j}(\boldsymbol{x})\right)\right\}+\rho \sum_{j=1}^{k} \mu_{j}\left(q_{j}-f_{j}(\boldsymbol{x})\right)
$$

which must be minimized in the feasible region:

$$
\begin{aligned}
& \min s(\boldsymbol{q}, f(\boldsymbol{x}), \boldsymbol{\mu}) \\
& \text { s.t.: } \quad \boldsymbol{x} \in X .
\end{aligned}
$$

The parameter $\rho>0$ is a so-called augmentation coefficient, which must be a small value and which assures the efficiency of the solutions generated (in many cases, $\rho$ is equal to one thousandth, or one ten thousandth). Only the weak efficiency of the solution is assured when the second term is not used, although, if the solution is unique, it is efficient (see [16]).

The problem (5.3) generates nondominated solutions and it is demonstrated that any Pareto optimal solution can be found by solving (5.3) using the ideal objective vector as reference point (or any objective vector that dominates it, as for example an utopian vector), and modifying the weight vector in the whole weight vector space [12]. It is also demonstrated that any Pareto optimal solution can be found by solving (5.3) when fixing the weight vector and varying the reference point [16].

Precisely, the property of being able to generate the whole Pareto optimal front using the ideal objective vector and/or utopian vector as reference point(s) in (5.3) is used in a recent group of evolutionary multiobjective algorithms to obtain an approximation of the Pareto optimal front. This group, called decomposition-based evolutionary multiobjective algorithms, transforms the original multiobjective optimization problem into a set of scalarizing (single-objective) optimization subproblems. During the solution process, the optimal individuals of these scalarizing subproblems are searched between the individuals of the current population. Among the most popular algorithms of this group we have MOEAD [29] and its different versions like for example the recent works of Qi et al. [19] and Wang et al. [25] where the adaptation of the weights is fundamental to obtain a better approximation.

Within this group, we also have Global WASF-GA (Global Weighting Achievement Scalarizing Function Genetic Algorithm) proposed by Saborido et al. [21] based on the achievement scalarizing function given in 
(5.2) and the use of two reference points (utopian and nadir points). It considers an initial predefined set of weight vectors whose inverse components are evenly distributed as much as possible. The idea is, taking into account the properties of (5.2), generate a set of projection directions evenly distributed as much as possible in the objective space. At each generation, the individuals (solutions) are classified into different fronts, as NSGA-II [6], according to the values that they take on (5.2) for the weight vectors. The convergence of the algorithm is assured by highlighting the individuals that minimize (5.2) at each generation.

Thus, our idea is to generate an approximation of the whole Pareto optimal front for our multiobjective model by using Global WASF-GA, analysing different solutions and trade-offs among them. To obtain a better approximation of the Pareto optimal front, we will also use the $L_{p}$ metric as achievement scalarizing function in Global WASF-GA so that we can obtain a broad and diverse set of nondominated solutions to our model. The use of different scalarized functions in decomposition-based evolutionary multiobjective algorithms have also been used in the well-known algorithm MOEA/D (see [25]), in a satisfying way, and allows to contrast the approximation obtained by considering (5.2).

Given the multiobjective problem (5.1), we also consider the following scalarizing function $(p \geq 1)$ :

$$
\mathrm{s}(\boldsymbol{z}, \mathrm{f}(\boldsymbol{x}), \boldsymbol{\mu})=\left[\sum_{j=1}^{k} \mu_{j}\left(z_{j}^{*}-f_{j}(\boldsymbol{x})\right)^{p}\right]^{1 / p}
$$

which must be minimized in the feasible region:

$$
\begin{aligned}
& \min \left[\sum_{j=1}^{k} \mu_{j}\left(z_{j}^{*}-f_{j}(\boldsymbol{x})\right)^{p}\right]^{1 / p} \\
& \text { s.t.: } \quad \boldsymbol{x} \in X .
\end{aligned}
$$

If $\mu_{j}>0$ for all $j=1, \ldots, k$, then a solution to (5.5) is Pareto optimal (see [27]). This formulation, proposed by $\mathrm{Yu}$ [27] and Zeleny [28], allows different grades of compensation between the objective values to reach their corresponding ideal values. Concretely, the higher is the $p$ value in (5.5), the lower is the compensation between objective values to reach the ideal vector (for $p=\infty$ there is no compensation between components and for $p=1$ the compensation is total). The difference between the ideal component and the objective value can be normalized by a range of the objective function.

In [1], it is demonstrated that, in the bi-objective case, if the efficient set is given by a continuously differentiable and strictly quasi-convex, then there is a narrow relation between the compromise set and a weighted problem combining the cases $p=\infty$ and $p=1$ of (5.5), that is, distances $L_{\infty}$ and $L_{1}$, respectively. In the majority of cases, the solution $L_{\infty}$ metric matches with the solutions to the problem (5.3) because $\rho$ is a small value. Concretely, the compromise set bounded by the solutions for $p=\infty$ and $p=1$ can be obtained varying the weights in the afore mentioned weighted problem (this last problem is similar to the achievement scalarizing function with the augmentation term proposed by Wierzbicki [26] where the augmentation term can vary from 0 to infinity). In the case without differentiability of the efficient set or with more than two objective functions, the relationship between both approaches practically does not exist. An extension to the problem (5.5) where the reference point is not necessary the ideal vector (can be unachievable or achievable), is proposed in Luque et al. [14].

\subsection{Constraints}

To have a model adjusted, as much as possible, to reality, it is necessary to define a set of constraints that delimit the possible values of the variables. These constraints have been derived from clear dependencies between explanatory variables. This means that we have chosen those pairs of variables whose dependencies were stronger according to this analysis. For example, we take the variable $x_{1}$ and observe the dependence between it and the rest of the variables, from where two-sided constraints have been built, using $99 \%$ confidence intervals; these bounds for $c$ and $d$ are presented in Table 2 . 
TABLE 2. Constraints for dependency between $x_{1}$ and $x_{2}, x_{3}, x_{4}$ or $x_{5}$.

\begin{tabular}{llllll}
\hline \hline Variables & Constraints & $c^{l}$ & $d^{l}$ & $c^{u}$ & $d^{u}$ \\
\hline \multirow{2}{*}{$x_{2}$} & C1 & 0.239 & 2.395 & & \\
& C2 & & & 0.647 & 5.391 \\
\hline$x_{3}$ & C3 & 0.331 & 2.920 & & \\
& C4 & & & 0.618 & 4.889 \\
\hline$x_{4}$ & C5 & 0.075 & 4.206 & & \\
& C6 & & & 0.398 & 6.591 \\
\hline$x_{5}$ & C7 & 0.115 & 5.017 & & \\
& C8 & & & 0.339 & 6.433 \\
\hline
\end{tabular}

Notes. Source: Authors' own calculations.

TABLE 3. Constraints for dependency between $x_{2}$ and $x_{3}, x_{4}$ or $x_{5}$.

\begin{tabular}{llllll}
\hline Variables & Constraints & $c^{l}$ & $d^{l}$ & $c^{u}$ & $d^{u}$ \\
\hline$x_{3}$ & C9 & 0.355 & 3.186 & & \\
& C10 & & & 0.607 & 4.913 \\
\hline$x_{4}$ & C11 & 0.398 & 2.717 & & \\
& C12 & & & 0.626 & 4.405 \\
\hline$x_{5}$ & C13 & 0.201 & 4.889 & & \\
& C14 & & & 0.389 & 6.077 \\
\hline
\end{tabular}

Notes. Source: Authors' own calculations.

TABLE 4. Constraints for dependency between $x_{3}$ and $x_{4}$ or $x_{5}$.

\begin{tabular}{llllll}
\hline \hline Variables & Constraints & $c^{l}$ & $d^{l}$ & $c^{u}$ & $d^{u}$ \\
\hline \multirow{2}{*}{$x_{4}$} & C15 & 0.392 & 1.522 & & \\
& C16 & & & 0.720 & 3.946 \\
\hline$x_{5}$ & C17 & 0.444 & 2.890 & & \\
& C18 & & & 0.629 & 4.058 \\
\hline
\end{tabular}

Notes. Source: Authors' own calculations.

Additionally, in Tables 3-5 we report the constraints of the rest of variables (in total we have 20 constraints). In these tables, the first row corresponds to the lower bounds of $c$ and $d$ and the second row corresponds to their upper bounds, for each variable. In order to make this procedure more understandable, an example is provided. We are going to use the variables $x_{1}$ and $x_{2}$; dependency between these variables is given by the following linear regression:

$$
x_{1}=c x_{2}+d
$$

where the confident intervals of the coefficients are (at 99\%): $c \in\left[c^{l}, c^{u}\right]=[0.239,0.647]$ and $d \in\left[d^{l}, d^{u}\right]=$ [2.395, 5.391], which implies:

$$
c^{l} x_{2}+d^{l} \leq x_{1} \leq c^{u} x_{2}+d^{u} .
$$

Apart from the restrictions defined above, we have considered the minimum and maximum of these variables in the database as lower and upper bounds. In Table 6, we show these bounds for each decision variable. 
TABLE 5. Constraints for dependency between $x_{4}$ and $x_{5}$.

\begin{tabular}{llllll}
\hline \hline Variables & Constraints & $c^{l}$ & $d^{l}$ & $c^{u}$ & $d^{u}$ \\
\hline$x_{5}$ & C19 & 0.254 & 4.188 & & \\
& C20 & & & 0.506 & 5.782 \\
\hline
\end{tabular}

Notes. Source: Authors' own calculations.

TABLE 6. Lower and upper bounds.

\begin{tabular}{llll}
\hline \hline Constraints & Lower bound & $x_{i}$ & Upper bound \\
\hline B1 & 5.5 & $x_{1}$ & 9.03 \\
B2 & 5.69 & $x_{2}$ & 9.27 \\
B3 & 4.92 & $x_{3}$ & 9.05 \\
B4 & 5.159 & $x_{4}$ & 9.435 \\
B5 & 3.543 & $x_{5}$ & 8.870 \\
\hline
\end{tabular}

Notes. Source: Authors' own calculations.

\subsection{Objective functions}

The objectives to be considered in this study are maximizing average scores in math and reading, and the proportion of students above level three in math and reading. The econometric study has allowed us to express these outcomes as functions of a set of five variables. Therefore, $\hat{\beta}_{m}^{j}$ is the regression coefficient of variable $m$ for performance level $j$, and $\widehat{\alpha}^{j}$ is the independent term of performance level $j$, then we have the following 4 objectives:

$$
\mathrm{EP}_{j}(\boldsymbol{x})=\left(\hat{\beta}^{j}\right)^{T} \boldsymbol{x}+\widehat{\alpha}^{j} \quad j=1,2,3,4 .
$$

where $\left(\hat{\beta}^{j}\right)^{T}=\left(\hat{\beta}_{1}^{j} \hat{\beta}_{2}^{j} \hat{\beta}_{3}^{j} \hat{\beta}_{4}^{j} \hat{\beta}_{5}^{j}\right)$ and $\boldsymbol{x}^{T}=\left(x_{1} x_{2} x_{3} x_{4} x_{5}\right)$. The resulting multiobjective problem to be solved is the following:

$$
\operatorname{Max}\left(\mathrm{EP}_{1}(\boldsymbol{x}), \mathrm{EP}_{2}(\boldsymbol{x}), \mathrm{EP}_{3}(\boldsymbol{x}), \mathrm{EP}_{4}(\boldsymbol{x})\right)=\left(\left(\hat{\beta}^{1}\right)^{T} \boldsymbol{x}+\widehat{\alpha}^{1},\left(\hat{\beta}^{2}\right)^{T} \boldsymbol{x}+\widehat{\alpha}^{2},\left(\hat{\beta}^{3}\right)^{T} \boldsymbol{x}+\widehat{\alpha}^{3},\left(\hat{\beta}^{4}\right)^{T} \boldsymbol{x}+\widehat{\alpha}^{4}\right) .
$$

Subject to: (C1)-(C20); (B1)-(B5).

For each case, we have calculated their ideal values:

$$
z^{*}=(553.932,557.249,0.400,0.487)^{T} .
$$

These ideal values are 553.932 points and 557.249 points, for math and reading, respectively. In terms of the other two outputs, the ideal values are $40 \%$ for students' above level three in math, and $48.7 \%$ for students' above level three in reading.

Although the number of significant variables that represent satisfaction is low (5.5), the correlation between the variables, expressed in the different constraints (20 in total), makes necessary to use appropriate techniques to generate the Pareto optimal front or a good approximation. It should be noted that the linear multiobjective problem in standard form has 35 variables $(5$ original variables +20 slack variables for inequality constraints and 10 slack variables for variable bounds) and 30 constraints (20 original constraints +10 constraints for variable bounds), which implies that the number of extreme points or vertices is at most $\left(\begin{array}{c}35 \\ 30\end{array}\right)=324632$, but 
nevertheless this number is usually smaller. Thus, as above mentioned, we have chosen to use Global WASFGA with different scalarized functions as fitness function to obtain a set of nondominated solutions which approximate the Pareto optimal front.

\subsection{Solutions to the multiobjective model}

As already mentioned, the multiobjective problem has been solved by the evolutionary multiobjective optimization (EMO) algorithm called Global WASF-GA. It is relevant to remark that, to the best of our knowledge, this is the first time that an EMO algorithm has been used to solve a multiobjective model defined for a case in economics of education.

To apply Global WASF-GA, firstly we need to calculate the ideal values or approximations. In order to obtain these values, it is necessary to maximize each objective function separately. Since the objective functions are not expressed on the same scale, we decided to work with normalized values for the objective functions as indicated in Section 4. Thus, the ideal values are given by:

$$
z_{1}^{*}=1.717, z_{2}^{*}=1.683, z_{3}^{*}=1.214, z_{4}^{*}=1.338 .
$$

Initially we do not have approximations of the nadirs and thus, we have decided to use Global WASF-GA considering only the ideal vector. Using the scalarized functions (5.2) and (5.4) for the values $p=1,2,5$, we have generated four approximations of the Pareto optimal front to our multiobjective model (5.6). The following values for the algorithm's parameters have been considered in the four runs:

- Number of weight vectors: 120 (generated so that the vectors formed by their inverse components are evenly distributed as much as possible).

- Number of iterations: 300.

- Maximum number of evaluations: $144.000(120 \times 300 \times 4)$.

- Crossover operator: SBX [6] with a distribution index $\eta_{c}=20$ and a probability $P_{c}=0.9$.

It has been implemented in Java and has been incorporated to the version 5 of jMetal framework $[8]^{5}$.

Once obtained these approximations, we have mixed the solutions of the four approximations remaining only with the nondominated solutions among them. As result, we have 31 solutions which are showed in Table 7 . The solutions are in decreasing order by the first objective function. It can be observed that when an objective is close to its ideal value, another objective value is far from its corresponding ideal value. For example, focusing on the first and last solutions it can be observed that in number one the value of scores in math is close to ideal while the value of percentage above level three in reading gets a low value. However, in the solution number thirty-one the opposite applies.

In order to have a better understanding of the solutions, the non-normalized solutions and the values of variables of the problem are shown in Tables A.3 and A.4, respectively. Also, in appendix (Tab. A.5), we show the descriptive statistics of solutions that approximate the Pareto optimal front. As it can be observed from Table A.3, with respect to math, mean scores in math, varies from 547.246 to 553.621 and the proportion of students with scores $\geq 559$ in math varies from 0.380 to 0.400 . In case of reading, mean scores varies from 553.832 to 557.097 and the proportion of students with scores above 559 varies from 0.476 to 0.486 . If we compare the mean scores in math and reading, they are in conflict since when math scores achieve the best value (553.621) reading achieves the worst value (553.832) and vice-versa. Same applies when comparing $\% \geq 559$ scores in math with $\% \geq 559$ scores in reading.

Regarding the decision variables of the solutions, the variable respect by teacher achieve a value close to the mean (respect by teacher's mean: 7.14), unlike the remaining decision variables, whose values are closer to the minimum than the average. It is logical since these variables have a negative influence on the objectives. Therefore, for obtaining a balance among the four objective functions (scores in math, scores in reading, $\% \geq 559$ scores in math, and \% $\geq 559$ scores in reading), the respect received by the teachers is relevant. On average,

\footnotetext{
${ }^{5}$ Which can be downloaded in https://github.com/jMetal/jMetal.
} 
TABLE 7. Normalized solutions.

\begin{tabular}{lllll}
\hline \hline $\begin{array}{l}\text { Number of } \\
\text { solution }\end{array}$ & $\begin{array}{l}\text { Normalized mean } \\
\text { scores in math }\end{array}$ & $\begin{array}{l}\text { Normalized mean } \\
\text { scores in reading }\end{array}$ & $\begin{array}{l}\text { Normalized } \% \geq 559 \\
\text { scores in math }\end{array}$ & $\begin{array}{l}\text { Normalized } \% \geq 559 \\
\text { scores in reading }\end{array}$ \\
\hline 1 & 1.709 & 1.600 & 1.213 & 1.268 \\
2 & 1.708 & 1.591 & 1.213 & 1.261 \\
3 & 1.706 & 1.602 & 1.213 & 1.269 \\
4 & 1.698 & 1.608 & 1.202 & 1.274 \\
5 & 1.696 & 1.607 & 1.204 & 1.274 \\
6 & 1.696 & 1.608 & 1.202 & 1.274 \\
7 & 1.692 & 1.609 & 1.202 & 1.275 \\
8 & 1.691 & 1.614 & 1.194 & 1.278 \\
9 & 1.690 & 1.612 & 1.194 & 1.284 \\
10 & 1.686 & 1.619 & 1.188 & 1.286 \\
11 & 1.683 & 1.622 & 1.184 & 1.289 \\
12 & 1.678 & 1.626 & 1.179 & 1.290 \\
13 & 1.675 & 1.627 & 1.177 & 1.284 \\
14 & 1.674 & 1.627 & 1.177 & 1.290 \\
15 & 1.666 & 1.619 & 1.185 & 1.305 \\
16 & 1.664 & 1.627 & 1.177 & 1.307 \\
17 & 1.653 & 1.646 & 1.150 & 1.310 \\
18 & 1.644 & 1.648 & 1.141 & 1.315 \\
19 & 1.642 & 1.652 & 1.139 & 1.307 \\
20 & 1.640 & 1.655 & 1.137 & 1.319 \\
21 & 1.634 & 1.658 & 1.132 & 1.319 \\
22 & 1.626 & 1.648 & 1.141 & 1.323 \\
23 & 1.626 & 1.662 & 1.139 & 1.307 \\
24 & 1.625 & 1.653 & 1.127 & 1.325 \\
25 & 1.623 & 1.662 & 1.119 & 1.3335 \\
26 & 1.616 & 1.667 & 1.132 & \\
27 & 1.614 & 1.658 & 1.117 & \\
28 & 1.614 & 1.647 & 1.096 & \\
29 & 1.612 & 1.669 & 1.072 & \\
30 & 1.584 & 1.674 & & \\
31 & 1.553 & 1.679 & & \\
\hline
\end{tabular}

Notes. Source: Authors' own calculations.

the results provide a solution where the score in math is 551.434 , the score in reading is 555.279 and the students' percentage reaching 559 points is $39.3 \%$ and $48.1 \%$ in math and reading, respectively. In this regard, the results suggest that it is easier achieve higher scores in math than reading.

\section{Conclusions}

An aspect that worries the Spanish educational authorities is the relative low performance of the Spanish students in terms of scores in international standardized assessments, grade repetition and dropout rates. This concern is even bigger in the case of the most populated Spanish region, i.e. Andalusia, which is the focus of our analyses.

In this context, the main purpose of this work has been to find which qualitative aspects of the teachinglearning process, in terms of the student's satisfaction, allow to obtain better results for the students' academic performance measured by scores in math and reading, and percentage of students reaching a certain threshold in both subjects. To this end, we have carried out a combined econometric and multiobjective analysis using data from a representative sample of secondary schools. Through linear regression, we have expressed the four 
objectives (scores in math and reading, and percentage of students reaching a certain threshold in both subjects) as functions of a set of explanatory variables: respect and attention received by the teachers, overall assessment of the teacher's way of teaching, information received on personal and academic progression, initial activities directed to the knowledge of the classmates and to the union of the group and knowledge of the projects and educational activities of the secondary school.

To solve our four-objective programming model, we have used a decomposition-based evolutionary multiobjective algorithm called Global WASF-GA with different scalarizing functions, which allows generating an approximation of the Pareto optimal front. The approach used, by which we obtain an approximation of the Pareto optimal front, provides a set of solutions that allows to identify the trade-offs among the objectives and the values reached by the decision variables in the different solutions.

The results obtained led us to think that there is scope to improve the Spanish educational system based on our main conclusions. Specifically, we claim that the respect and attention received by teachers is very important to promote higher levels of students' academic performance. For this reason, the authorities must establish educational policies that promote respect and narrower interaction between students and teachers. A potential way to improve this is to make available to the students a few hours in which pupils can talk with their tutors and teachers, to make easier the student-teacher mutual understanding and to promote a better teaching-learning environment. Furthermore, the authorities should settle periodical evaluations to check the satisfaction of teachers and students in terms of mutual interaction.

Finally, as future lines of research, it could be of interest to analyse alternative ways of evaluating the students' performance, besides the quantitative assessment, i.e. to account for students non-cognitive skills and well-being, which can be considered as objectives of the problem.

\section{Appendix A.}

TABLE A.1. Descriptive statistics for the satisfaction variables.

\begin{tabular}{|c|c|c|c|c|}
\hline & \multicolumn{4}{|c|}{ Std. } \\
\hline & Mean & Dev. & Min & $\operatorname{Max}$ \\
\hline State in which the facilities and equipment of the center are & 6.66 & 0.85 & 3.52 & 8.90 \\
\hline Satisfaction with the use made of the facilities and equipment of the center & 6.80 & 0.75 & 4.52 & 8.73 \\
\hline $\begin{array}{l}\text { Satisfaction with the cleaning and decoration of the installations and equipment } \\
\text { of the secondary school }\end{array}$ & 6.46 & 0.83 & 4.17 & 9.00 \\
\hline Provision of the student body to recommend the center & 7.28 & 0.80 & 5.00 & 9.23 \\
\hline Utility of the response given to the complaint or claim presented & 5.72 & 1.04 & 3.26 & 9.32 \\
\hline Response time to the complaint or claim presented & 5.99 & 1.09 & 3.33 & 9.22 \\
\hline Overall assessment of the teacher's way of teaching & 7.33 & 0.53 & 5.69 & 9.27 \\
\hline Information received about the criteria established to pass the course & 7.20 & 0.50 & 5.68 & 8.98 \\
\hline Information received about the criteria established to obtain a title & 7.36 & 0.52 & 6.04 & 9.81 \\
\hline Overall assessment of the organization and operation of the center & 7.04 & 0.75 & 4.59 & 9.57 \\
\hline Assessment of extracurricular activities & 7.25 & 0.63 & 5.70 & 9.09 \\
\hline Assessment of complementary activities & 6.00 & 1.29 & 2.12 & 9.35 \\
\hline Operation of support classes in the afternoon & 6.48 & 1.08 & 3.88 & 8.85 \\
\hline Respect and attention received by the teachers & 7.14 & 0.58 & 5.50 & 9.03 \\
\hline Knowledge of the rules of coexistence & 7.62 & 0.52 & 6.44 & 9.41 \\
\hline Working of the coexistence classroom & 6.40 & 0.76 & 4.19 & 9.13 \\
\hline Information received on personal and academic progression & 6.82 & 0.69 & 4.92 & 9.05 \\
\hline $\begin{array}{l}\text { Initial activities directed to the knowledge of the classmates and to the union of } \\
\text { the group }\end{array}$ & 7.36 & 0.71 & 5.16 & 9.43 \\
\hline Information about the academic possibilities after finishing the studies & 7.12 & 0.60 & 4.83 & 8.96 \\
\hline Knowledge about the academic centers where to continue the studies & 7.13 & 0.89 & 4.88 & 9.56 \\
\hline Knowledge of the projects and educational activities of the secondary school & 6.25 & 0.98 & 3.54 & 8.87 \\
\hline
\end{tabular}

Notes. Source: Authors' own calculations. 
TABLE A.2. Labeling of the variables under scrutiny.

\begin{tabular}{|c|c|c|c|c|c|}
\hline Name & Notation & Variable & Type & Values & Description \\
\hline \multirow[t]{3}{*}{ Math } & $y_{1}$ & $\begin{array}{l}\text { Mean scores in mathe- } \\
\text { matics }\end{array}$ & & & \\
\hline & & Not normalized & Cont. & {$[357.189,587.69]$} & $\begin{array}{l}\text { Mean of students' marks in mathemat- } \\
\text { ics by center }\end{array}$ \\
\hline & & Normalized & Cont. & {$[-2.40,2.55]$} & $\begin{array}{l}\text { Normalized mean of students' marks in } \\
\text { mathematics by center }\end{array}$ \\
\hline \multirow[t]{3}{*}{ Reading } & $y_{2}$ & Mean scores in reading & & & \\
\hline & & Not normalized & Cont. & {$[373.62,571.99]$} & $\begin{array}{l}\text { Mean of students' marks in reading by } \\
\text { center }\end{array}$ \\
\hline & & Normalized & Cont. & {$[-2.74,2.04]$} & $\begin{array}{l}\text { Normalized mean of students' marks in } \\
\text { reading by center }\end{array}$ \\
\hline \multirow[t]{3}{*}{ Level4Math } & $y_{3}$ & $\begin{array}{l}\text { Percentage of students } \\
\text { above level four in } \\
\text { math }\end{array}$ & & & \\
\hline & & Not normalized & Cont. & {$[0,0.61]$} & $\begin{array}{l}\text { Percentage of students who perform } \\
\text { above level four ( } 559 \text { points) in math }\end{array}$ \\
\hline & & Normalized & Cont. & {$[-41.63,2.69]$} & $\begin{array}{l}\text { Normalized percentage of students } \\
\text { who perform above level four ( } 559 \\
\text { points) in math }\end{array}$ \\
\hline \multirow[t]{3}{*}{ Level4Reading } & $y_{4}$ & $\begin{array}{l}\text { Percentage of students } \\
\text { above level four in } \\
\text { reading }\end{array}$ & & & \\
\hline & & Not normalized & Cont. & {$[0,0.66]$} & $\begin{array}{l}\text { Percentage of students who perform } \\
\text { above level four ( } 559 \text { points) in read- } \\
\text { ing }\end{array}$ \\
\hline & & Normalized & Cont. & {$[-1.91,2.51]$} & $\begin{array}{l}\text { Normalized percentage of students } \\
\text { who perform above level four ( } 559 \\
\text { points) in reading }\end{array}$ \\
\hline $\begin{array}{l}\text { Respect by } \\
\text { teachers }\end{array}$ & $x_{1}$ & & Cont. & {$[5.5,9.03]$} & $\begin{array}{l}\text { Respect and attention received by the } \\
\text { teachers }\end{array}$ \\
\hline Way to teach & $x_{2}$ & & Cont. & {$[5.69,9.27]$} & $\begin{array}{l}\text { Overall assessment of the teacher's way } \\
\text { of teaching }\end{array}$ \\
\hline Progression & $x_{3}$ & & Cont. & {$[4.92,9.05]$} & $\begin{array}{l}\text { Information received on personal and } \\
\text { academic progression }\end{array}$ \\
\hline $\begin{array}{l}\text { Starting } \\
\text { activities }\end{array}$ & $x_{4}$ & & Cont. & {$[5.16,9.43]$} & $\begin{array}{l}\text { Initial activities directed to the knowl- } \\
\text { edge of the classmates and classmates } \\
\text { as well as to the union of the group }\end{array}$ \\
\hline $\begin{array}{l}\text { Projects and } \\
\text { activities }\end{array}$ & $x_{5}$ & & Cont. & {$[3.54,8.87]$} & $\begin{array}{l}\text { Knowledge of the projects and educa- } \\
\text { tional activities of the secondary school }\end{array}$ \\
\hline
\end{tabular}

Notes. Source: Authors' own calculations. 
TABLE A.3. Non-normalized solutions.

\begin{tabular}{lllll}
\hline \hline $\begin{array}{l}\text { Number of } \\
\text { solution }\end{array}$ & $\begin{array}{l}\text { Mean scores } \\
\text { in math }\end{array}$ & $\begin{array}{l}\text { Mean scores } \\
\text { in reading }\end{array}$ & $\begin{array}{l}\% \geq 559 \\
\text { scores in } \\
\text { math }\end{array}$ & $\begin{array}{l}\% \geq 559 \\
\text { scores in } \\
\text { reading }\end{array}$ \\
\hline 1 & 553.621 & 553.832 & 0.400 & 0.476 \\
2 & 553.575 & 553.460 & 0.400 & 0.475 \\
3 & 553.490 & 553.887 & 0.400 & 0.476 \\
4 & 553.164 & 554.148 & 0.398 & 0.477 \\
5 & 553.103 & 554.121 & 0.399 & 0.477 \\
6 & 553.085 & 554.157 & 0.399 & 0.477 \\
7 & 552.923 & 554.178 & 0.398 & 0.477 \\
8 & 552.863 & 554.389 & 0.397 & 0.478 \\
9 & 552.858 & 554.324 & 0.397 & 0.478 \\
10 & 552.688 & 554.619 & 0.396 & 0.479 \\
11 & 552.542 & 554.740 & 0.396 & 0.479 \\
12 & 552.363 & 554.885 & 0.395 & 0.479 \\
13 & 552.240 & 554.931 & 0.395 & 0.479 \\
14 & 552.186 & 554.930 & 0.395 & 0.479 \\
15 & 551.850 & 554.621 & 0.396 & 0.479 \\
16 & 551.783 & 554.931 & 0.395 & 0.479 \\
17 & 551.332 & 555.710 & 0.391 & 0.482 \\
18 & 550.950 & 555.797 & 0.390 & 0.482 \\
19 & 550.872 & 555.954 & 0.390 & 0.483 \\
20 & 550.818 & 556.091 & 0.389 & 0.483 \\
21 & 550.559 & 556.204 & 0.389 & 0.483 \\
22 & 550.255 & 555.796 & 0.390 & 0.482 \\
23 & 550.244 & 556.369 & 0.388 & 0.484 \\
24 & 550.205 & 555.997 & 0.390 & 0.483 \\
25 & 550.133 & 556.367 & 0.388 & 0.484 \\
26 & 549.825 & 556.584 & 0.387 & 0.484 \\
27 & 549.762 & 556.221 & 0.389 & 0.483 \\
28 & 549.757 & 555.763 & 0.390 & 0.482 \\
29 & 549.654 & 556.675 & 0.386 & 0.485 \\
30 & 548.513 & 556.885 & 0.383 & 0.485 \\
31 & 547.246 & 557.097 & 0.380 & 0.486 \\
\hline
\end{tabular}

Notes. Source: Authors' own calculations. 
TABLE A.4. Value of decision variables.

\begin{tabular}{llllll}
\hline \hline $\begin{array}{l}\text { Solution } \\
\text { number }\end{array}$ & $\begin{array}{l}\text { Respect by } \\
\text { teachers }\end{array}$ & Way to teach & Progression & $\begin{array}{l}\text { Starting } \\
\text { activities }\end{array}$ & $\begin{array}{l}\text { Projects and } \\
\text { activities }\end{array}$ \\
\hline 1 & 7.932 & 5.778 & 4.925 & 5.312 & 4.423 \\
2 & 7.929 & 5.778 & 4.920 & 5.335 & 4.417 \\
3 & 7.927 & 5.781 & 4.920 & 5.309 & 4.409 \\
4 & 7.907 & 5.765 & 4.921 & 5.295 & 4.351 \\
5 & 7.910 & 5.775 & 4.920 & 5.297 & 4.359 \\
6 & 7.909 & 5.772 & 4.922 & 5.295 & 4.354 \\
7 & 7.907 & 5.779 & 4.921 & 5.294 & 4.350 \\
8 & 7.891 & 5.757 & 4.920 & 5.283 & 4.303 \\
9 & 7.892 & 5.757 & 4.920 & 5.288 & 4.304 \\
10 & 7.879 & 5.747 & 4.920 & 5.272 & 4.267 \\
11 & 7.871 & 5.742 & 4.920 & 5.266 & 4.243 \\
12 & 7.862 & 5.736 & 4.920 & 5.258 & 4.214 \\
13 & 7.858 & 5.738 & 4.920 & 5.256 & 4.204 \\
14 & 7.858 & 5.741 & 4.920 & 5.256 & 4.204 \\
15 & 7.875 & 5.789 & 4.921 & 5.272 & 4.255 \\
16 & 7.858 & 5.765 & 4.920 & 5.256 & 4.204 \\
17 & 7.806 & 5.703 & 4.920 & 5.217 & 4.050 \\
18 & 7.788 & 5.695 & 4.920 & 5.215 & 3.998 \\
19 & 7.784 & 5.693 & 4.921 & 5.203 & 3.991 \\
20 & 7.780 & 5.690 & 4.920 & 5.198 & 3.975 \\
21 & 7.771 & 5.690 & 4.920 & 5.192 & 3.947 \\
22 & 7.788 & 5.737 & 4.920 & 5.216 & 3.997 \\
23 & 7.760 & 5.690 & 4.920 & 5.184 & 3.915 \\
24 & 7.785 & 5.735 & 4.920 & 5.202 & 3.988 \\
25 & 7.760 & 5.697 & 4.920 & 5.184 & 3.915 \\
26 & 7.745 & 5.690 & 4.920 & 5.173 & 3.872 \\
27 & 7.771 & 5.738 & 4.920 & 5.191 & 3.948 \\
28 & 7.789 & 5.768 & 4.920 & 5.217 & 4.001 \\
29 & 7.741 & 5.693 & 4.920 & 5.168 & 3.859 \\
30 & 7.700 & 5.692 & 4.920 & 5.164 & 3.739 \\
31 & 7.654 & 5.690 & 4.920 & 5.159 & 3.610 \\
\hline
\end{tabular}

Notes. Source: Authors' own calculations. 
TABLE A.5. Statistics of solutions.

\begin{tabular}{lllllll}
\hline \hline & \multicolumn{2}{c}{ Mean } & \multicolumn{2}{c}{ Min } & \multicolumn{2}{c}{ Max } \\
\cline { 2 - 7 } & Normalized & $\begin{array}{l}\text { Non } \\
\text { normalized }\end{array}$ & Normalized & $\begin{array}{l}\text { Non } \\
\text { normalized }\end{array}$ & Normalized & $\begin{array}{l}\text { Non } \\
\text { normalized }\end{array}$ \\
\hline $\begin{array}{l}\text { Mean scores } \\
\text { in math }\end{array}$ & 1.655 & 551.434 & 1.553 & 547.246 & 1.709 & 553.621 \\
$\begin{array}{l}\text { Mean scores } \\
\text { in reading }\end{array}$ & 1.635 & 555.279 & 1.591 & 553.460 & 1.679 & 557.097 \\
$\begin{array}{l}\% \geq 559 \\
\text { scores in }\end{array}$ & 1.162 & 0.393 & 1.072 & 0.380 & 1.213 & 0.400 \\
$\begin{array}{l}\text { math } \\
\% \geq 559\end{array}$ & 1.297 & 0.481 & 1.261 & 0.475 & 1.335 & 0.486 \\
$\begin{array}{l}\text { scores in } \\
\text { reading }\end{array}$ & & & & & & \\
\hline
\end{tabular}

Notes. Source: Authors' own calculations.

Acknowledgements. This research has been partially supported by the Spanish Ministry of Economy, Industry and Competitiveness (ECO2017-88883-R) and by Andalusian Regional Ministry of Economy, Knowledge, Business and University (PAI group SEJ-532 and UMA18-FEDERJA-024 also supported by FEDER funding). Sandra González Gallardo is recipient of a technical research contract within "Sistema Nacional de Garantía Juvenil y del Programa Operativo de Empleo Juvenil 2014-2020 - Fondos FEDER", also acknowledges the training received from the University of Malaga Ph.D. Programme in Economy and Business (Programa de Doctorado en Economía y Empresa de la Universidad de Malaga).

\section{REFERENCES}

[1] F.J. André and C. Romero, Computing compromise solutions: on the connections between compromise programming and composite programming. Appl. Math. Comput. 195 (2008) 1-10.

[2] R.J. Barro, Human Capital and Growth. Am. Econ. Rev. 91 (2001) 12-17.

[3] J. Calero and O. Escardíbul, El rendimiento del alumnado de origen inmigrante en PISA 2012, edited by INEE. In: Vol. II of Análisis secundario PISA 2012: Programa para la evaluación internacional de los alumnos. Informe español. Ministerio de Educación, Cultura y Deporte, Instituto Nacional de Evaluación Educativa, Madrid (2013) 4-31.

[4] J.F. Chizmar and T.A. Zak, Source modeling multiple outputs in educational production functions. Am. Econ. Rev. 73 (1983) $18-22$.

[5] K. Deb and K. Miettinen, Nadir point estimation using evolutionary approaches: better accuracy and computational speed through focused search, edited by M. Ehrgott, B. Naujoks, T.J. Stewart and J. Wallenius. In: Multiple Criteria Decision Making for Sustainable Energy and Transportation Systems. Springer-Verlag, Berlin (2010) 339-354.

[6] K. Deb, A. Pratap, S. Agarwal and T. Meyarivan, A fast and elistic multiobjective genetic algorithm: NSGA-II. IEEE Trans. Evol. Comput. 6 (2002) 182-197.

[7] K. Deb, K. Miettinen and S. Chaudhuri, Towards an estimation of nadir objective vector using a hybrid of evolutionary and local search approaches. IEEE Trans. Evol. Comput. 14 (2010) 821-841.

[8] J.J. Durillo and A.J. Nebro, jMetal: A java framework of multi-objective optimization. Adv. Eng. Softw. 42 (2011) $760-771$.

[9] M. Ehrgott and D. Tenfelde-Podehl, Computation of ideal and nadir values and implications for their use in MCDM methods. Eur. J. Oper. Res. 151 (2003) 119-139.

[10] S. Gibbons and O. Silva, School quality, child wellbeing and parents' satisfaction. Econ. Edu. Rev. 30 (2011) $312-331$.

[11] E. Hanushek and L. Woessmann, The economics of international differences in educational achievement, edited by E. Hanushek, S. Machin and L. Woessmann. In: Vol. 3 of Handbook of the Economics of Education. Elsevier, New York (2011) 89-200.

[12] I. Kaliszewski, Quantitative Pareto Analysis by Cone Separation Technique. Kluwer Academic Publishers, Dordrecht (1994).

[13] M. Luque, O.D. Marcenaro and L.A. Lopez-Agudo, On the potential balance among compulsory education outcomes through econometric and multiobjetive programming analysis. Eur. J. Oper. Res. 241 (2015) 527-540.

[14] M. Luque, A.B. Ruiz, R. Saborido and O.D. Marcenaro, On the use of the Lp distance in reference point-based approaches for multiobjective optimization. Ann. Oper. Res. 235 (2015) 559-579.

[15] O.D. Marcenaro, M. Luque and L.A. Lopez-Agudo, Balancing teachers' math satisfaction and other indicators of the education system's performance. Soc. Indic. Res. 129 (2016) 1319-1348.

[16] K. Miettinen, Nonlinear Multiobjective Optimization. Kluwer Academic Publishers, Boston (1999).

[17] G.K. Natvig, G. Albrektsen and U. Qvarnstrom, Associations between psychosocial factors and happiness among school adolescents. Int. J. Nursing Pract. 9 (2003) 166-175. 
[18] OECD, PISA 2015 Results in Focus, PISA, OECD Publishing, Paris. https://www.oecd.org/pisa/ pisa-2015-results-in-focus.pdf (2018).

[19] Y. Qi, X. Ma, F. Liu, L. Jiao, J. Sun and J. Wu, MOEA/d with adaptive weight adjustment. Evol. Comput. 22 (2014) $231-264$.

[20] R.W. Rumberger and G.J. Palardy, Test scores, dropout rates, and transfer rates as alternative indicators of high school performance. Am. Edu. Res. J. 42 (2005) 3-42.

[21] R. Saborido, A.B. Ruiz and M. Luque, Global WASF-GA: An evolutionary algorithm in multiobjective optimization to approximate the whole pareto optimal front. Evol. Comput. 25 (2017) 309-349.

[22] S. Suldo, E. Shaffer and K. Riley, A social-cognitive-behavioral model of academic predictors of adolescents' life satisfaction. School Psychol. Q. 23 (2008) 56-69.

[23] S.M. Suldo, A. Thalji-Raitano, M. Hasemeyer, C. Gelley and B. Hoy, Understanding middle school students life satisfaction: Does school climate matter? Appl. Res. Q. Life 8 (2013) 169-182.

[24] C. Uline and M. Tschannen-Moran, The walls speak: the interplay of quality facilities, school climate and student achievement. J. Edu. Admin. 46 (2008) 55-73.

[25] R. Wang, Q. Zhang and T. Zhang, Descomposition - Based algorithms using pareto adaptive scalarazing methods. IEEE Trans. Evol. Comput. 20 (2016) 821-837.

[26] A.P. Wierzbicki, The use of reference objectives in multiobjective optimization, edited by G. Fandel and T. Gal. In: Multiple Criteria Decision Making. Theory and Applications. Springer-Verlag, Berlin (1980) 468-486.

[27] P.L. Yu, A class of solutions for group decision problems. Manage. Sci. 19 (1973) 936-946.

[28] M. Zeleny, A concept of compromise solutions and the method of the displaced ideal. Comput. Oper. Res. 1 (1974) 479-496.

[29] Q. Zhang and H. Li, MOEA/D: A multiobjective evolutionary algorithm based on decomposition. IEEE Trans. Evol. Comput. 1 (2007) 712-731. 